\title{
Duas almas, muitas assombrações e o corpo da história
}

Gildo Marçal BRANDÃO. A esquerda positiva. As duas almas do Partido Comunista1920/1964. São Paulo, Hucitec, 1997. 290 páginas.

\section{Luiz Eduardo Soares}

O livro de Gildo Marçal Brandão sobre o Partido Comunista Brasileiro, originalmente tese de doutorado defendida na USP, é uma dessas raríssimas obras que nascem para ser referência obrigatória e interlocução incontornável. Enquanto não houver melhor definição para um clássico, a qualificação é absolutamente apropriada a $A$ esquerda positiva, editado pela Hucitec em 1997. Aí está um livro recém-lançado e já destinado à posteridade. Não haveria precipitação no julgamento, talvez decorrente do fato de que o autor da resenha se identifique inteiramente com as conclusões do resenhado? Poderia, uma tese acadêmica, projetar-se diretamente da banca para as prateleiras permanentes da consciência histórica nacional? Como regra geral, certamente a resposta seria negativa. Mas há casos excepcionais. Recordo-me de um exemplo, do qual dou testemunho por ter tido o privilégio de resenhá-lo com o mesmo entusiasmo, antecipando-lhe idêntico destino. Refiro-me a Araweté: os deuses canibais, de Eduardo Viveiros de Castro. Dez anos depois, refaço a aposta, evocando, em meu benefício, a correção de meu juízo anterior, cujo tom superlativo chocou, à época, alguns colegas.
Em primeiro lugar, assinale-se que o livro ultrapassa o horizonte de problemas aludidos no título para projetar seu foco reflexivo bem além das esquerdas, de seus nichos doutrinários, de seus guetos ideológicos, de suas infindáveis querelas normativas. Sem negligenciar a relevância dos conflitos internos ao PCB ou a natureza autoritária e em vários sentidos perversa de sua estrutura organizacional, respeitando a importância dos demais afluentes que se desgarraram da matriz comunista, Gildo Marçal Brandão opta, entretanto, por rastrear o sentido histórico da participação do PCB na vida política do país e nas transformações que a sociedade brasileira sofreu ao longo do século XX. Em o fazendo, elabora uma perspectiva de leitura do processo histórico que o distancia da tradição circular das polarizações político-intelectuais, em cujos termos, ora se justificam, ora se criticam os posicionamentos do PCB, sempre a partir de convicções sobre o modelo da revolução brasileira, a classe operária e seu papel, o caráter de nosso capitalismo etc. Nesse sentido, não só a dimensão positiva da participação política do PCB é destacada e analisada, como a própria abordagem analítica é positiva não confundir com positivista , na medida em que as intervenções conjunturais (de efeitos estritamente 
contingentes ou estruturais) do partido não são avaliadas por contraste com uma suposta linha justa, ou um padrão idealizado, deduzido da doutrina ou de eventual interpretação anacrônica, teleológica, ingênua e post-factum. As intervenções são tomadas como movimentos de um ator político determinado, sociologicamente circunscrito, cuja eficácia cabe investigar, nos mais diversos planos que uma abordagem histórica desdobra diante do pesquisador. Assim como os partidos burgueses que atuaram na República liberal de 1945 são estudados pelo que acrescentaram ao mundo real da política brasileira, e não por seus déficits ante possíveis expectativas derivadas de suas ideologias de origem, também o PCB mereceu, enfim, o seu momento de consciência analítica. Positividades, ao invés dedéficits prático-ideológicos; intervenções tópicas concretas e interpelações dos agentes políticos e sociais; implicações em esferas diversas da formação social; relações de cooperação e conflito: esse o campo complexo e dinâmico de objetos recortado pela perspectiva teórica adotada.

Se o livro alcança um universo muito mais amplo do que o condomínio freqüentemente autofágico e familiar da esquerda, é sobretudo porque redescreve, com originalidade e audácia, a República liberal de 1945, centro de gravitação de nossa história política no século XX. Não gostaria que esse destaque correspondesse à subestimação das contribuições que o livro oferece para o entendimento das lutas políticas das classes subalternas nos anos 20, para o esclarecimento da importância extraordinária da frente popular que se gestava na ANL até 1935, para a dinâmica que tornou possível a derrocada da democracia em 1964, ou mesmo para as semelhanças e diferenças entre os vários PCs latino-americanos, sobre as quais o autor reuniu indicações preciosas. Há, inclusive, ótimos insights sobre o período ditatorial e a resistência democrática. No entanto, o centro estratégico da análise concentra-se, a meu ver, na descoberta do "ovo de Colombo". Vistas a posteriori, as grandes descobertas parecem óbvias, quase extensões da natureza, que se desnudaria transparente e plenamente inteligível. Gildo Marçal Brandão, pela primeira vez nas ciências sociais brasileiras, identifica, com precisão e profundidade, a (i)legalidade do PCB como um fator tão decisivo quão invisível para a compreensão de um e de outro, isto é: da República semidemocrática de 1945 e dos próprios rumos do partido. E isso não é pouco. Se não, vejamos: o que afirmo é que, sem a incorporação desse fator, a ilegalidade do PCB, não podemos compreender adequadamente a dinâmica política da República liberal de 1945. Tampouco podemos analisar apropriadamente partidos, eleições, alienação eleitoral, participação eleitoral, perfis partidários, competição política institucionalizada, o lugar e a função da estrutura sindical corporativa herdada do Estado Novo, a relação da classe operária e dos trabalhadores do campo com a ordem política, com os partidos políticos e com as eleições, ou a relação das classes subalternas consigo próprias, mediada por formas de consciência necessariamente dependentes de mecanismos organizativos. Em outras palavras: cessa o que a antiga musa canta, no que tange ao estudo do regime de 1945 e de sua institucionalidade política. Não quero dizer que tudo o que aprendemos a respeito desse período esteja errado. De modo algum. O que sim afirmo é que tudo o que sabemos deve, agora, a partir da obra de Gildo Marçal Brandão, ser revisto, sofrer inflexões, ser contrastado com o novo quadro interpretativo e render-se à sua imprescindível mediação analítica.

Ouso algumas interrogações contrafactuais, apenas para facilitar a exposição de minha hipótese quanto à importância absolutamente fundamental do achado de Gildo: com um partido operário legal, que relações o movimento sindical tenderia a estabelecer com a estrutura corporativa? Com o eventual descolamento de lideranças operárias da estrutura de cooptação, que novas tensões e colaborações poder-se-iam verificar entre a política partidária, o sindicalismo e os movimentos sociais das classes subalternas? Que impacto tais mudanças poderiam produzir sobre o padrão excludente e autoritário de desenvolvimento do capitalismo brasileiro? Que implicações uma eventual democratização de nosso padrão de desenvolvimento imporia à própria energia da evolução das forças produtivas? Legais, os comunistas redistribuiriam de que modo os votos populares entre as 
legendas disponíveis, reconhecendo-se, inclusive, o extraordinário caráter nacional do PCB? Por outro lado, operando na legalidade, o PCB renunciaria ao jogo democrático para investir na aventura isolacionista, insurrecional, golpista, que o afastou do eixo da vida social por tantos anos? Dotado de responsabilidades, cohabitando governos, praticando alianças, não estaria o PCB mais bem situado para compreender o dinamismo do capitalismo brasileiro, as chances positivas da institucionalidade democrática, a autonomia relativa da ordem política, a relevância e a especificidade dos regimes políticos? Essa compreensão, esses compromissos e responsabilidades não condenariam o PCB a converter-se em esteio da legalidade e obstáculo a aventuras golpistas? O padrão populista da política democrática não sofreria mutação radical? Legal, o PCB poderia ter sido, como foi, tão refratário a participações eleitorais (ao contrário do que diz o mito que o condena, pasmem!, por ser eleitoreiro), tão negligente quanto à participação em governos locais, à elaboração de políticas construtivas ou de alternativas positivas? Observe-se que a reorientação para a participação positiva, celebrada na Declaração de março de 1958, corresponde, justamente, ao período em que se consolida a ascensão do PCB a umstatus de semilegalidade consentida.

Claro que a contrafactualidade é um método caprichoso de persuasão, dado que, à negação fáctica, segue-se, em princípio, um número imenso de alternativas. Todos os mundos possíveis alternativos tornam-se, automaticamente, legítimos ante a suspensão hipotética da história fenomênica. De todo modo, justifica-se, nesse caso, o recurso ao argumento contrafactual, dada a consistência e plausibilidade dos cursos de ação alternativos assinalados, e suas implicações para a avaliação das conseqüências da ilegalidade do PCB, seja para o sistema político, a sociedade brasileira ou o destino do próprio partido.

Aí reside a fonte da duplicidade aludida no título: "as duas almas". Duas gravitações impeliram o PCB para duas rotas opostas de ação política, poder-se-ia dizer, sintetizando e empobrecendo um pouco os resultados da exploração intelectual de Gildo Marçal Brandão: a participação na ordem institucional (gravitação da ordem legaldemocrática) e a assimilação da ilegalidade (gravitação da clandestinidade, de seus fantasmas e de suas fantasias), ditada pela exclusão autoritária e classista do pseudoliberalismo brasileiro e (paradoxal, mas compreensivelmente) corroborada pela auto-exclusão de um marxismo-leninismo dogmático, estreito e sectário, votado ao golpismo no qual se combinavam certa modalidade pequeno-burguesa de tenentismo esquerdista com o voluntarismo vanguardista.

Não seria impertinente, creio, reconhecer, por meio de uma leitura que os anos 70 chamariam "sintomal", a presença de uma teoria subjacente à análise sócio-histórica e política apresentada em $A$ esquerda positiva. Eis uma forma possível de enunciá-la, brevemente: a institucionalidade política democrática deve ser apreendida, conceitualmente, pelo ângulo de uma dupla positividade, capaz de detectar, por um lado, a dinâmica de seu funcionamento ou a eficácia de seu mecanismo de resolução de problemas, e, por outro lado, o rendimento de seus dispositivos de deslocamento de problemas, de redução de turbulências e remoção de obstáculos à sua reprodução estável.

A estabilidade, portanto, não seria mera superposição entre os domínios das variáveis (a) operação institucional articulada do mercado político e (b) restrição de demandas por poder a um grau compativel com o estoque da oferta de bens politicos, ou seja, função da mecânica institucional imersa na dinâmica sóciohistórica correspondente, mas o eventual resultado empírico, historicamente produzido, do choque contingente entre o processo de reprodução (ele próprio irregular e problemático) de determinados tipos instituídos de dominação e o curso assumido pela interpelação que os agentes excluídos dirigem ao sistema institucional.* Esse curso, por sua vez, depende da lógica que preside tal interpelação, que a faz variar do pleito por inclusão ao aprofundamento da rota de marginalização. A ponta extrema da dispersão realiza-se como guerra civil; a ponta oposta, integracionista, cumpre-se como corrosão da legitimidade do sistema institucional. Nos dois casos, evidencia-se o caráter positivo tanto da estabilidade quanto 
da instabilidade institucionais, dado que ambas resultam de correlações de forças tópicas, mais ou menos expressivas de composições mais permanentes e estruturais. Em outras palavras, a instabilidade deixa de ser pensada como um defeito no funcionamento de um mecanismo destinado a reproduzir-se concepção que, curiosamente, despolitiza a política para domesticá-la como objeto previsível da ciência behaviorista. A instabilidade está inscrita como virtualidade nos sistemas institucionais que regulam a distribuição social de poder, na medida em que, nos sistemas, inclusões e exclusões são dispositivos (não necessariamente interdependentes) eficientes e correspondem a deslocamentos empíricos de atores, atuais ou potenciais.

Se essa descrição vale para todo e qualquer sistema político, mesmo os liberal-democráticos, o que não dizer de sistemas híbridos, ostensivamente excludentes, como o que se impôs no Brasil entre 1947 e 1964? Claro sintoma da negligência com que a bibliografia tratou a exclusão do PCB é a definição do regime de 1945 como uma estrutura uniforme, que se teria preservado até o golpe de 1964. A decretação, em 1947, da ilegalidade do Partido Comunista surge como mais um episódio que se dá no interior do marco institucional erigido em 1945. Como se esse deslocamento não representasse uma mudança dramática na natureza mesma dessa institucionalidade, alterando drasticamente as condições de pertencimento e de exclusão à ordem política de agentes, valores, interesses e projetos nacionais. Como se esse deslocamento, mudando a relação entre as duas dimensões do sistema (suas duas positividades: o que se inclui e o que se exclui), não implicasse transformações significativas nas relações entre as classes sociais e entre essas e a ordem política. Como se, finalmente, a ordem política se restringisse às instituições, reificadas e idealisticamente autonomizadas, descarnadas de conteúdo sociológico e de pregnância histórica.

A oscilação histórica do PCB motivou dois resultados paradoxais, mas de modo algum incomuns: fortaleceu a coalizão politicamente dominante quando se lançou na aventura insurrecional, degradando em golpismo a estratégia cumulativa e politicamente conseqüente do front populaire (1935), e enfraqueceu a institucionalidade democrática, renunciando a investir em sua legitimidade, quando, na prática, manobrava na direção integracionista e já não se beneficiava da corrosão da legitimidade, decorrente de sua própria exclusão institucional (1964).

Faça-se justiça ao livro: sua prudência elegante e sofisticada o faz manter o foco da análise nos efeitos da (i)legalidade sobre a fortuna do PCB, que lhe obstruíram a virtude política. Apenas vicariamente $A$ esquerda positiva deriva conseqüências para a República liberal de 1945. Esse registro modesto e seguro garante a força persuasiva de seus argumentos, mas inibe a explicitação e o desenvolvimento de uma perspectiva mais ampla, capaz de generalizar princípios interpretativos, como aqueles a que aludi acima, em meu próprio inventário das concepções que suponho subjacentes à obra. Ao resenhista perdoam-se algumas aventuras hermenêuticas, que à obra possivelmente subtrairiam solidez. Portanto, longe de uma cobrança crítica, minha leitura pessoal da dimensão reflexiva que ouso denominar implícita é somente o esforço de reconhecimento da magnitude da contribuição da obra em pauta, que me parece ultrapassar os limites dos quais ela própria está consciente.

Revirando de ponta-cabeça o regime de 1945, Gildo propõe interrogações sobre a própria teoria democrática, em sua generalidade. É o que pretendi sugerir com minha ênfase nos desdobramentos da ilegalidade do PCB para a institucionalidade política, em seu conjunto. E o que está sendo problematizado é bastante grave. Não só para o conhecimento de nosso passado, como para nossas idéias relativas à democracia hoje. Idéias que circulam na academia como conceitos e que se difundem na sociedade como ideologias. Se toda institucionalidade democrática exclui e inclui, variando apenas os graus em que atuam os dispositivos correspondentes, a democracia deixa de ser "o mal MENOR" para submeter-se ao exame crítico, ideológico e/ou teórico como "o MAL menor". O deslocamento da ênfase tem implicações muito mais significativas do que talvez se imagine em um primeiro momento. Hoje, quando quase todos somos democratas, talvez ainda possamos sê-lo respeitando a tradição que 
distinguia os adversários na Assembléia revolucionária de 1789 entre esquerda e direita. O traço distintivo talvez possa situar-se no ponto em que se concentra a ênfase na sentença acima, popularizada por sirWinston Churchill. Em palavras mais simples e diretas: (1) pode-se abordar a democracia como uma forma de organização do domínio social e da violência política. A forma menos resistente, historicamente inventada, a mudanças na estrutura de distribuição de riqueza e poder, rumo à maximização simultânea nos limites do historicamente possível das variáveis que definem, em cada sociedade específica, a atualização da eqüidade (ou justiça) e da liberdade; (2) ou pode-se, inversamente, abordá-la como a realização institucional do equilíbrio cooperativo entre atores políticos congeniais, portadores de interesses conflitivos, em um contexto de bens simultaneamente escassos (posicionais) mas ilimitados (resultantes de produtividade difusa, contínua e heterogênea). Cada uma dessas perspectivas teóricas é indissociável de compromissos valorativos e ideológicos, e identifica, diversamente, tanto as responsabilidades do pesquisador, quanto suas qualidades. A primeira concepção recusa a autonomização absoluta da esfera política, cujo sentido histórico é considerado indissociável da radicação sociológica das dinâmicas institucionais. A segunda concepção circunscreve empiricamente a institucionalidade política, examinando a lógica estrutural de suas dinâmicas, pressupondo a congenialidade entre os atores e a possibilidade de descrevê-los axiomaticamente, com independência dos processos empíricos, o que desloca a Sociologia, a Antropologia, a História, a Psicologia e as substitui pela matriz econômica do individualismo utilitário. O maior risco da primeira concepção talvez seja o subjetivismo impressionista do ensaio, enquanto a armadilha mais perigosa da segunda abordagem talvez seja a metodolatria fetichista e reificadora.

Creio que a opção clara de $A$ esquerda positiva pela primeira forma de abordagem logrou êxito exatamente na medida em que veio acompanhada de cuidados contra os riscos do impressionismo. A extensão da pesquisa empírica e historiográfica levada a cabo pelo autor consolidou uma plataforma segura para a formulação de hipóteses interpretativas consistentes. Gildo Marçal Brandão levou crítica e respeitosamente em consideração toda a bibliografia referente à história política brasileira no período coberto por sua pesquisa, além da literatura dedicada ao PCB. Consultou toda a documentação relevante e ouviu os principais personagens que sobreviveram à história de lutas, erros e heroísmos. Dialogou com todas as formulações teóricas pertinentes, de modo a circunscrever seu objeto com o máximo rigor.

$\mathrm{Na}$ obra, a adjetivação positiva surge com quatro significados distintos, sobre os quais já me detive, direta ou indiretamente. Cumpre-me, agora, sintetizar o percurso descritivo: (1) de imediato, positiva é a esquerda que contribui para a solução concreta de problemas sociais; participa da elaboração de programas de governo; orienta políticas públicas; dirige a ação de seus militantes no sentido da conquista, no interior dos marcos legais, de benefícios que signifiquem avanços, do ponto de vista da eqüidade; assume responsabilidades institucionais; ou pressiona os demais atores, demandando integrar-se à ordem política democrática, para ampliá-la e aprofundá-la; (2) positiva é também a perspectiva epistemológica e metodológica do autor, que constrói seu objeto como espectro de positividades historicamente contextualizadas, e não como espectro judicativo oriundo de standard normativo, teleológico, doutrinário, anacrônico , que regula a distância entre o que deveria ter sido e o que efetivamente foi; (3) finalmente, positivas são, em minha leitura do subtexto do autor, ambas as dimensões da dinâmica institucional democrática constitutivas, com idêntico direito à cidadania conceitual, da ordem política: inclusão e exclusão. (4) Conclui-se, portanto, que registrar o caráter excludente do regime que se redefine em 1947 significa acrescentar uma dimensão relevante à descrição de sua objetividade. A exclusão dos comunistas não é o avesso (o negativo) da ordem semidemocrática da República liberal (uma espécie de custo, incompletude ou limitação), mas um fator indispensável ao seu funcionamento, um aspecto necessário daquilo que ela é. Donde, não se diz o que ela é omitindo a presença eficiente desse fator. 
Ao concluírem a leitura de $A$ esquerda positiva, independentemente de sua persuasão ideológica e já alertados pelo próprio autor para os equívocos e as mesquinharias que se avolumam na tradição comunista, creio que os leitores atentos se inclinarão a reconhecer a dignidade histórica do PCB e a centralidade de seu papel no processo de modernização da sociedade brasileira, nos mais diversos planos.

Gildo Marçal Brandão cita Hegel, recorre a seus conceitos, prolonga-os até o sistema categorial marxista, mas evita assumir compromisso filosófico restritivo. Sua linguagem, no entanto, não deixa margem a dúvidas: lá estão, em toda sua complexidade e não como simples peça de retórica , o movimento dialético e suas mediações, que se desdobram e se articulam nos momentos produtivos e reveladores do todo, da totalidade histórica, e em sua síntese gnoseológica. Graças à linguagem de Hegel, Gildo escapa das armadilhas do marxismo, com suas entediantes e estéreis disputas escolásticas sobre determinação e autonomia. Graças às categorias marxistas e gramscianas, Gildo evita o evolucionismo idealista hegeliano, em cujos termos a história reduz-se à antecipação racional do fim ou à realização da razão. Essa flexibilidade pode lhe ser creditada ao invés de debitada sob o estigma "ecletismo" como solução engenhosa para combinar as noções (todas úteis e, por vezes, indispensáveis) de progresso, contradição, imprevisibilidade ou incerteza, indeterminação, recuos, saltos, processos não lineares, autonomia da agência humana e condicionamentos restritivos, acaso e necessidade, contingência e reprodução estrutural. A sensibilidade analítica capaz de acompanhar os movimentos do objeto, na medida em que o constrói, exige essa ampla disponibilidade para reter, dos processos sociais, as mais surpreendentes manifestações de autonomia tanto de agentes quanto de níveis estruturais, assim como os momentos de determinação mais restritivos. A combinação plástica produz uma linguagem conceitual unívoca, coordenada pela abertura radicalmente antidogmática à positividade do processo histórico, em suas múltiplas esferas, analiticamente distinguíveis. Por isso mesmo, o estudo da política, na obra de Gildo Brandão, alcança o nível superior e sintético dos estudos sociais, porque articula dicções disciplinares diversas, paradigmas teóricos diferentes e matrizes metodológicas distintas. O resultado condensa a erudição do autor com a sofisticação, plena de nuances, de suas reflexões. Nada mais distante da salada inconseqüente com que, algumas vezes, o trabalho trans, inter ou multidisciplinar é confundido.

No entanto, cabe a interrogação: o autor precisa da ontologia hegeliana para produzir os resultados que obteve? Necessita supor a exterioridade dicotômica realrepresentação, com a qual opera? Precisa da noção de verdade como correspondência entre conhecimento e realidade? Além disso, de fato, os resultados de sua investigação não poderiam ser alcançados se partisse da suposição de que o que chama "real" não é senão o produto de sua descrição, à qual deseja imputar validade intelectual (ou valor de verdade)? Sua obra naufragaria em "idealismo" se fosse mais tolerante e generosa com os autores que investem no estudo do imaginário, do simbólico, do cultural, das percepções sociais ou das ideologias, e que recusam o objetivismo, mesmo o dialético? O fato (a meu juízo circunstancial e aleatório) de que tais autores (refirome aos citados no livro) compartilham determinada interpretação equivocada e anacrônica do processo político teria de ser, necessariamente, atribuído às teorias construtivistas de que partem?

Do meu ponto de vista, todas as respostas a essas perguntas são negativas. Eu próprio me proponho como exemplo do que sustento: discordo da perspectiva filosófica neohegeliana adotada por Gildo, discordo de sua teoria da verdade e do conhecimento, não compartilho sua linguagem ontológica, essencialista e realista, mas concordo inteiramente com todas as teses analíticas defendidas pela obra. Talvez isso demonstre que as crenças metateóricas não são tão importantes assim, desde que não atrapalhem a abertura à complexidade multidimensional e à dinâmica tortuosa do processo histórico. Ou que, ao contrário, tais crenças são importantes e fazem diferença, promovendo a flexibilidade hermenêutica desejável e compatível com o desafio heurístico. Nesse caso, ter-se-ia de incluir um proviso: tais efeitos da metateoria são cruciais, mas muitas 
crenças filosóficas, muitos jogos de linguagem podem servir a esse propósito. Somente a posteriori essa utilidade poderia ser avaliada. Se essa proposição soar aceitável, eu estaria em condições de sugerir uma metainterrogação, referente ao plano metateórico: que teorias ou filosofias admitiriam esse convívio promíscuo de princípios e essa lassidão do juízo? De minha posição pragmática, sinto-me confortável à espera da resposta. Por assim dizer, não tenho pressa. À paciência do conceito aqui se acrescenta a indiferença para com o que, na prática, mesmo da análise, não faz diferença.

A esquerda positiva postula, ainda, alguns princípios gerais com os quais me identifico plenamente, e que julgo da maior relevância divulgar. Eis como os leio: (1) qualquer crítica, para ter sentido político, isto é, ter conseqüência prática (ou validade legitimidade histórica), tem de apoiarse em alternativa inscrita, ainda que como virtualidade, na constelação diagnosticada das variáveis em presença; (2) o desenvolvimento das forças produtivas ou o progresso tecnológico é um eixo crucial e estratégico, porque as inovações que decorrem de sua dinâmica constituem instrumentos eficientes de mudança nas relações sociais e na distribuição de poderes (assim como constituem fatores transformadores das formas de vida, que são, a um só do. tempo, conjuntos de práticas, valores, idéias, imagens, sensibilidades, percepções, emoções, disposições protonormativas etc.); (3) dos postulados anteriores decorre uma concepção evolucionária da história, que reconhece acúmulos mas não nega, a priori, obstruções, retrocessos, dispêndios, instabilidades, saltos etc.; (4) se as metas ideológicas dos democratas radicais ainda são aquelas do esclarecimento, da revolução burguesa, de nossa tradição judaico-cristã e do marxismo igualdade, ou justiça, e liberdade (se possível, fraternidade) , os instrumentos analíticos e conceituais, por sua vez, têm de conceber-se como históricos e subordinados aos processos sobre os quais se debruçam analiticamente, o que infunde humildade cognitiva ao estudioso, relativizando e contextualizando suas próprias perspectivas.

Daí à desmontagem da ontologia realista e essencialista, há um passo mas, são várias as opções filosóficas possíveis e legítimas. Essa variedade, um saudável pluralismo deve estimular, para que o debate acadêmico se enriqueça e, quem sabe, para que a política volte a ocupar espíritos inspirados pela vocação, ao invés de reduzir-se, exclusivamente, a um saber técnico, apêndice instrumental e, eventualmente, descartável do merca

\section{LUIZ EDUARDO SOARES}

é professor do Instituto Universitário de Pesquisas do Rio de Janeiro (Iuperj) e da Universidade do Estado do Rio de Janeiro.

* É preciso ter presente que a tradição do pensamento político conservador moderno, pelo menos desde Burke, sempre prezou, ostensivamente, a redução ao mínimo indispensável do espectro da incorporação direta de atores e classes sociais, pela via da representação parlamentar orgânica, na ordem política. Desde que a expropriação de meios políticos não provoque resistência capaz de pôr em risco a segurança de todo o sistema institucional, a exclusão tem sido defendida como mecanismo de ampliação da estabilidade institucional e das condições do que os conservadores contemporâneos têm chamado" governabilidade". Portanto, não é privilégio da esquerda interpretar a exclusão como positividade. A direita a pratica e a transforma em discurso conceitual, também como positividade, sem nenhum constrangimento. 